\title{
Validation of a CFD Methodology for Variable Speed Power Turbine Relevant Conditions
}

\section{Ali A. Ameri}

The Ohio State University, Columbus, Ohio

Paul W. Giel

Vantage Partners, LLC, Cleveland, Ohio

Ashlie B. McVetta

Glenn Research Center, Cleveland, Ohio 


\section{NASA STI Program . . . in Profile}

Since its founding, NASA has been dedicated to the advancement of aeronautics and space science. The NASA Scientific and Technical Information (STI) program plays a key part in helping NASA maintain this important role.

The NASA STI Program operates under the auspices of the Agency Chief Information Officer. It collects, organizes, provides for archiving, and disseminates NASA's STI. The NASA STI program provides access to the NASA Aeronautics and Space Database and its public interface, the NASA Technical Reports Server, thus providing one of the largest collections of aeronautical and space science STI in the world. Results are published in both non-NASA channels and by NASA in the NASA STI Report Series, which includes the following report types:

- TECHNICAL PUBLICATION. Reports of completed research or a major significant phase of research that present the results of NASA programs and include extensive data or theoretical analysis. Includes compilations of significant scientific and technical data and information deemed to be of continuing reference value. NASA counterpart of peer-reviewed formal professional papers but has less stringent limitations on manuscript length and extent of graphic presentations.

- TECHNICAL MEMORANDUM. Scientific and technical findings that are preliminary or of specialized interest, e.g., quick release reports, working papers, and bibliographies that contain minimal annotation. Does not contain extensive analysis.

- CONTRACTOR REPORT. Scientific and technical findings by NASA-sponsored contractors and grantees.
- CONFERENCE PUBLICATION. Collected papers from scientific and technical conferences, symposia, seminars, or other meetings sponsored or cosponsored by NASA.

- SPECIAL PUBLICATION. Scientific, technical, or historical information from NASA programs, projects, and missions, often concerned with subjects having substantial public interest.

- TECHNICAL TRANSLATION. Englishlanguage translations of foreign scientific and technical material pertinent to NASA's mission.

Specialized services also include creating custom thesauri, building customized databases, organizing and publishing research results.

For more information about the NASA STI program, see the following:

- Access the NASA STI program home page at http://www.sti.nasa.gov

- E-mail your question to help@sti.nasa.gov

- Fax your question to the NASA STI Information Desk at 443-757-5803

- Phone the NASA STI Information Desk at 443-757-5802

- Write to: STI Information Desk NASA Center for AeroSpace Information 7115 Standard Drive Hanover, MD 21076-1320 


\title{
Validation of a CFD Methodology for Variable Speed Power Turbine Relevant Conditions
}

\author{
Ali A. Ameri
}

The Ohio State University, Columbus, Ohio

Paul W. Giel

Vantage Partners, LLC, Cleveland, Ohio

Ashlie B. McVetta

Glenn Research Center, Cleveland, Ohio

Prepared for the

Turbo Expo 2013

sponsored by the American Society of Mechanical Engineers (ASME)

San Antonio, Texas, June 3-7, 2013

National Aeronautics and

Space Administration

Glenn Research Center

Cleveland, Ohio 44135 
This report is a preprint of a paper intended for presentation at a conference.

Because changes may be made before formal publication, this preprint is made available with the understanding that it will not be cited or reproduced without the permission of the author.

Trade names and trademarks are used in this report for identification only. Their usage does not constitute an official endorsement, either expressed or implied, by the National Aeronautics and Space Administration.

This work was sponsored by the Fundamental Aeronautics Program at the NASA Glenn Research Center.

Level of Review: This material has been technically reviewed by technical management.

Available from

NASA Center for Aerospace Information 7115 Standard Drive

Hanover, MD 21076-1320
National Technical Information Service 5301 Shawnee Road Alexandria, VA 22312

Available electronically at http://www.sti.nasa.gov 


\title{
Validation of a CFD Methodology for Variable Speed Power Turbine Relevant Conditions
}

\author{
Ali A. Ameri \\ The Ohio State University \\ Columbus, Ohio 43235 \\ Paul W. Giel \\ Vantage Partners, LLC \\ Brook Park, Ohio 44142 \\ Ashlie B. McVetta \\ National Aeronautics and Space Administration \\ Glenn Research Center \\ Cleveland, Ohio 44135
}

\begin{abstract}
Analysis tools are needed to investigate aerodynamic performance of Variable-Speed Power Turbines (VSPT) for rotorcraft applications. The VSPT operates at low Reynolds numbers (transitional flow) and over a wide range of incidence. Previously, the capability of a published threeequation turbulence model to predict accurately the transition location for three-dimensional heat transfer problems was assessed. In this paper, the results of a post-diction exercise using a three-dimensional flow in a transonic linear cascade comprising VSPT blading are presented. The measured blade pressure distributions and exit total pressure and flow angles for two incidence angles corresponding to cruise $\left(i=5.8^{\circ}\right)$ and takeoff $\left(i=-36.7^{\circ}\right)$ were used for this study. For the higher loading condition of cruise and the negative incidence condition of takeoff, overall agreement with data may be considered satisfactory but areas of needed improvement are also indicated.
\end{abstract}

\section{Nomenclature}

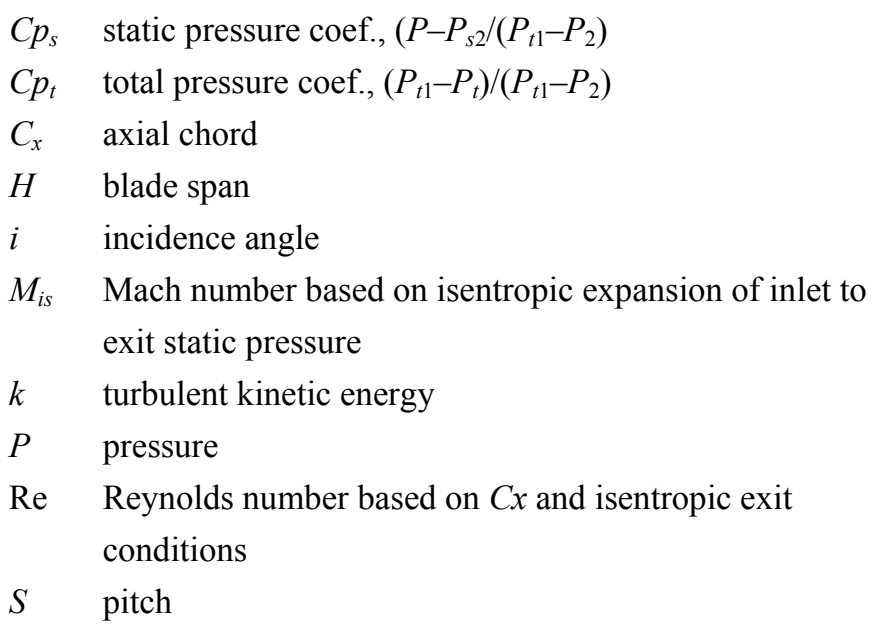

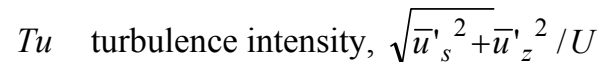

$u^{\prime}$ fluctuating component of velocity

$U$ incoming free stream velocity

$x \quad$ axial coordinate

$y$ pitchwise coordinate

$z \quad$ spanwise coordinate

\section{Greek}

$\beta \quad$ pitch angle (deg.)

$\delta \quad$ upstream endwall boundary layer thickness

$\omega$ specific dissipation of turbulence

$\Omega \quad$ gradient of velocity at the wall

\section{Subscripts}

1 based on inlet condition

2 based on exit condition

$t$ total value

$x \quad$ local value, or axial value

$s \quad$ streamwise component

$z \quad$ spanwise component

\section{Introduction}

Development of civil rotorcraft to enhance airspace throughput capacity and diminish airport congestion is a key goal of NASA's Rotary Wing Project. One concept that could contribute to those goals is the use of Large Civil Tilt-Rotor (LCTR) aircraft to enable vertical takeoff and landing as well as high speed cruise (Refs. 1 and 2). In order to optimize fuel efficiency, the main-rotor speed is varied from 100 percent at takeoff to 55 percent at cruise. This can be achieved by using a two-speed transmission driven by a power turbine with minimal turbine speed change (Ref. 3). In order to avoid the 
added weight and complexity of a two-speed transmission, a variable speed power turbine (VSPT) can be used with a fixed gear ratio transmission. Variations in the shaft speed of the VSPT lead to a wide $\left(40^{\circ}\right.$ to $\left.60^{\circ}\right)$ range of incidence at Reynolds numbers in the laminar or transitional range (Ref. 4), resulting in flow conditions that are difficult to analyze accurately. VSPTs share the low Reynolds number conditions with low pressure turbines which have been reported to suffer loss of efficiency at higher altitudes under cruise conditions (Refs. 5 to 7). Such low Reynolds number conditions allow for the existence of laminar boundary layers on the blade surfaces. Laminar boundary layers are prone to separation, producing large losses and deviation if not reattached. Positive incidence increases blade loading and strengthens the vortical secondary flow structures, and can induce flow separation on the suction-side. Negative incidence unloads the blade and makes for a more two-dimensional flow. Three-dimensional pressure-side cove separation occurs under conditions of extreme negative incidence (Ref. 8). Computational Fluid Dynamics (CFD) computations (Ref. 9) of a blade in a linear cascade under large negative angles also exhibited vortical structures aligned in the spanwise direction on the pressure-side cove. Since the test blade was a linear cascade, the vortex realigned itself to flow direction near the midspan of the linear blade. For an actual turbine blade such a vortex would realign itself to the direction of the flow and spill out near the tip (Ref. 8).

Accurate prediction of losses under the conditions noted above is a challenge for steady CFD. The state of the boundary layer (laminar, transitional, or turbulent) has a large effect on the aerodynamic losses and thus a realistic prediction of the flow depends on its accurate modeling; further, the impact of deterministic unsteadiness of upstream and adjacent blade rows, neglected in the present analysis, is known to have a measurable effect on loss levels of transitional flows (Ref. 6). Analysis tools are needed to investigate the penalties associated with maintaining efficient VSPT operation over a wide shaft-speed change.

In a previous study (Ref. 9), the capabilities of a published transition/turbulence model, namely the Walters-Leylek Three-Equation model (Refs. 10 and 11), was assessed. Threedimensional heat transfer data on a blade were used to mark transition for the computational exercise. Subsequent to establishing satisfactory model performance as it pertained to transition, computed loss for the Energy Efficient Engine $\left(E^{3}\right)$ blade set (Refs. 12 and 13) was presented. This first-stage high-pressure-turbine blade-tip profile geometry had been tested in a linear cascade with zero tip clearance and varying inlet incidence angle (Ref. 13). The total pressure deficits at the exit for a wide range of incidence angles were computed. It was noted that losses were generated by the endwall and blade boundary layers and were transported and augmented by the horseshoe and passage vortices. At high negative incidences, pressure-side separation and roll-up of the resulting vortex into a streamwise vortex was illustrated and for positive incidence, it was shown that secondary flows strengthen and widen as the loading on the blades increases with the incidence angle. Comparison with wake profiles at midspan (Ref. 13) for the $\mathrm{E}^{3}$ blade using the present methodology was given in Reference 14 where the predictive capability using Walters-Leylek model was shown to be quite good for the incidence angles at the extreme limits.

\section{Transition Modeling}

In an earlier report (Ref. 9), results were obtained with Walters and Leylek turbulence model. It was noted that among the benefits of using this model was the freedom from having to compute near-wall integral quantities, which are difficult to evaluate in complex three-dimensional flows. Transport equations for transition and turbulence use phenomenological models, as opposed to empirically based models (Refs. 10 and 11 ), and do not require computation of any boundary layer or integral quantities. In the work presented by Walters and Leylek (Ref. 11), a modified form of the $k-\omega$ model supplemented with a transport equation for the "laminar kinetic energy," forms a three-equation model. A study conducted by Cutrone et al. (Ref. 15) consisting of several models, including other popular models, showed the threeequation model approach to be promising. Subsequent application (Ref. 16) to two-dimensional flows and to a threedimensional turbine cascade showed good agreement with experiments and superior comparison to other models attempted in that paper and an earlier report. It should be noted that in References 15 and 16, the model (Refs. 10 and 11) was implemented without the submodel for natural transition, presumably in anticipation of high turbulence levels.

\section{Objectives}

In the present study, the flow field in a three-dimensional transonic linear cascade was computed in order to assess pressure distribution, midspan loss levels and exit flow angles. This was motivated by the availability of relevant VSPT threedimensional data recently obtained at the NASA Glenn Research Center (Ref. 17). Two distinct conditions were considered and sensitivity to grid density and to variables such as turbulence length scale and inlet boundary layer thickness was investigated. The objective was to verify the predictive capabilities (and limitations, thereof) of a method of computing flows of relevance to the VSPT. The method involves a RANS solution of the flow field using the turbulence/transition model of Walters and Leylek (Refs. 10 and 11). The test article for the experimental program was a scaled two-dimensional extruded VSPT blade designed to meet the specified engine requirement (Ref. 18), and adapted for a cascade test (Ref. 17). The measurements were taken at various Reynolds numbers and Mach numbers, and covered a wide range of incidence angles. Blade pressure loading measurements at multiple span locations as well as exit total- 
pressure surveys in the wake were performed. Prediction of the pressure distribution, which is routine for attached flows, is often a challenge when the boundary layer separation is involved. The flow in this cascade is strongly threedimensional due to the high flow turning and an inlet boundary layer that covers approximately one quarter of the span.

The CFD work performed to compute the pressure distribution and total-pressure coefficient and exit angle for the VSPT blade geometry at the "cruise" and "takeoff" incidence angles, and comparison to the experimental data of McVetta et al. (Ref. 17) will be reviewed.

\section{VSPT Blade Experiment}

A description of the cascade and a summary of the conditions for the experimental measurements used for this numerical validation are provided here.

NASA Glenn Transonic Turbine Blade Cascade Facility is shown in Figure 1. The cascade's large scale and continuous run capability at engine relevant Mach numbers and Reynolds numbers have allowed for detailed heat transfer and aerodynamic studies on a wide range of turbine blades. The blade geometry used in this test was a scaled two-dimensional midspan section of the VSPT second stage rotor (Ref. 18) shown in Figure 2 and the blade description is given in Table 1. The cascade for this test was made up of nominally ten blade passages. The blades were attached to a disk that can be rotated to set inlet flow angles (from axial) in the range $-17^{\circ} \leq \beta_{1} \leq 78.8^{\circ}$. During this test, ten incidence angles were examined (Ref. 17). Detailed three-dimensional flowfield data were acquired at incidence angles of $5.8^{\circ}\left(\beta_{1}=40.0^{\circ}\right)$ and $-36.7^{\circ}\left(\beta_{1}=-2.5^{\circ}\right)$, which represent the cruise and takeoff flight mission points, respectively. These two mission points were used in the CFD verification for this current study. The angle settings are given in Table 2. The flow conditions listed in Table 3 are the nominal conditions under which the CFD tests were run. The lowest achievable tunnel Reynolds number condition was higher than those at cruise. In order to admit transitional flow appropriate to altitude conditions, no turbulence grid was used during this test (Ref. 17). In a previous study (Ref. 13) the inlet turbulence intensity without a turbulence grid was documented to range from 0.25 to 0.40 percent. McVetta et al. (Ref. 17) suggest that future plans will include testing at higher turbulence intensity.

To allow the determination of the inlet length scale of turbulence, the turbulence for the present experiments was measured at two stations 4.5 and 0.5 axial- chords upstream of the blade row. These data, which will be shown in the computational section of the paper, were used to compute a turbulence length scale for use as an inlet boundary condition for the computations.

Table 3 provides the experimental conditions which can be used in the simulations.

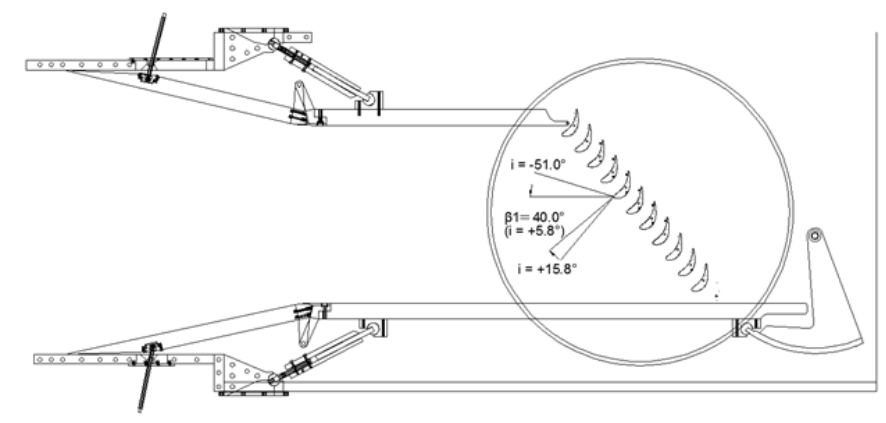

Figure 1.-Overall view of NASA Glenn's transonic cascade facility.
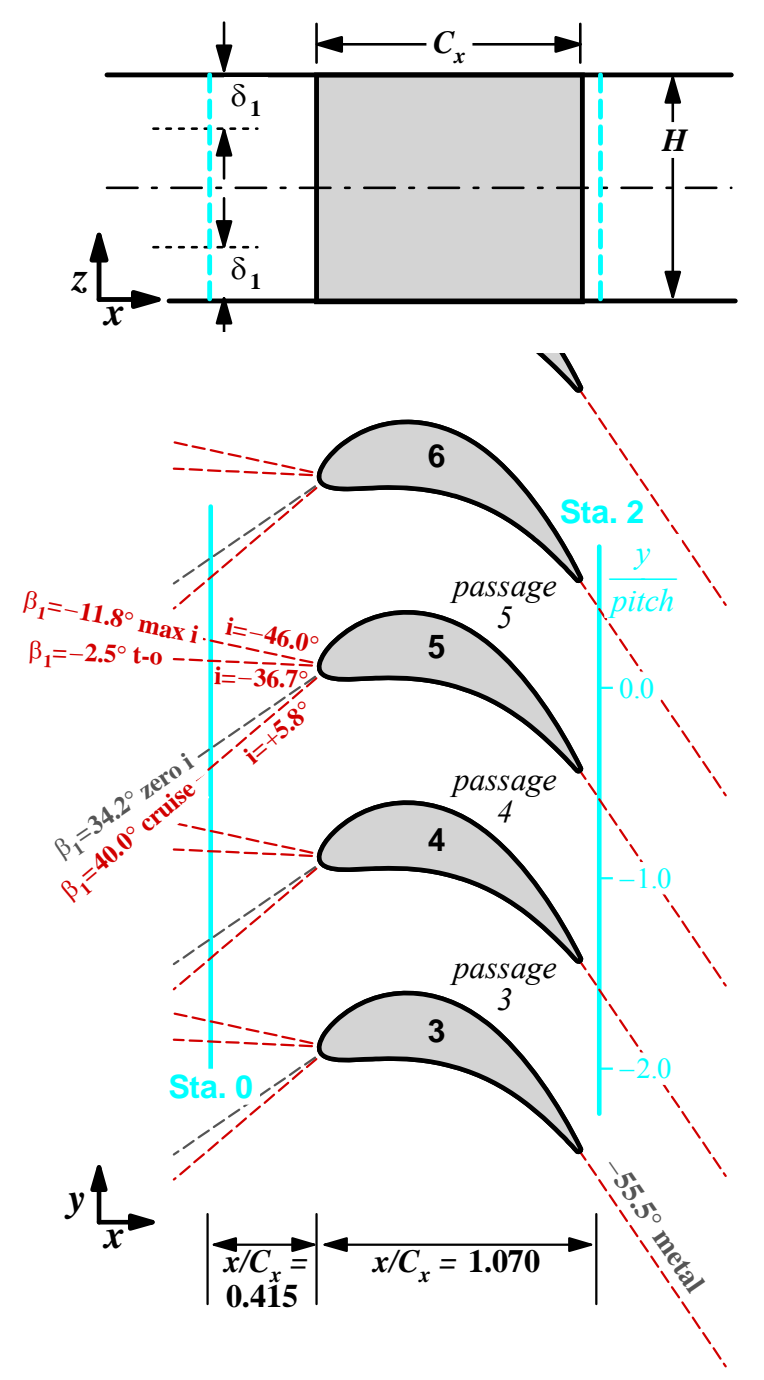

Figure 2.-Blade geometry and exit survey plane location. 
TABLE 1.-BLADE DESCRIPTION

\begin{tabular}{|l|l|}
\hline \multicolumn{1}{|c|}{ Geometry } & \multicolumn{1}{|c|}{ Value } \\
\hline Axial chord, $C_{x}$ & $180.57 \mathrm{~mm}(7.109$ in.) \\
True chord & $194.44 \mathrm{~mm}(7.655$ in. $)$ \\
Pitch, $S$ & $130.00 \mathrm{~mm}(5.119$ in. $)$ \\
Span, $H$ & $152.40 \mathrm{~mm}(6.000$ in.) \\
Throat diameter & $72.85 \mathrm{~mm}(2.868$ in. $)$ \\
Leading edge diameter & $15.16 \mathrm{~mm}(0.597$ in.) \\
Trailing edge diameter & $3.30 \mathrm{~mm}(0.130$ in.) \\
Stagger angle & $20.35^{\circ}$ \\
Inlet metal angle & $34.2^{\circ}$ \\
Uncovered turning & $19.47^{\circ}$ \\
Exit metal angle & $-55.54^{\circ}$ \\
\hline
\end{tabular}

TABLE 2.-ANGLE SETTINGS

\begin{tabular}{|c|c|}
\hline $\begin{array}{c}\text { Inlet angle, } \\
\beta_{1}\end{array}$ & $\begin{array}{c}\text { Incidence angle, } \\
i\end{array}$ \\
\hline $40.0^{\circ}$ (Cruise) & $5.8^{\circ}$ \\
\hline$-2.5^{\circ}$ (Takeoff) & $-36.7^{\circ}$ \\
\hline
\end{tabular}

TABLE 3.-FLOW CONDITIONS USED IN THE SIMULATIONS

\begin{tabular}{|c|c|c|c|c|c|c|}
\hline $\begin{array}{c}\text { Inlet } \\
\text { angle, } \\
\beta_{1}\end{array}$ & $\begin{array}{c}\text { Exit } \\
\operatorname{Re}_{C x}\end{array}$ & $\begin{array}{c}\text { Press. } \\
\text { ratio }\end{array}$ & $\begin{array}{c}\text { Exit } \\
M_{I S}\end{array}$ & $\begin{array}{c}\delta_{\text {inlet }} \\
\text { in. }\end{array}$ & $\begin{array}{c}T u_{\text {in }} \% \\
\text { at } \\
-5.0 C_{x}\end{array}$ & $\begin{array}{c}T u_{\text {in }} \% \\
\text { at } \\
-0.5 C_{x}\end{array}$ \\
\hline $40.0^{\circ}$ & 536,000 & 1.412 & 0.72 & 1.44 & 0.4 & 0.3 \\
\hline$-2.5^{\circ}$ & 532,000 & 1.348 & 0.67 & 1.50 & ${ }^{\mathrm{a}} 0.4$ & ${ }^{\mathrm{a}} 0.3$ \\
\hline
\end{tabular}

As shown in Figure 2, the inlet conditions were measured at Station 0 , located approximately 0.5 axial-chords upstream of the cascade. For the present study total-pressure and exit flow angle data were acquired using a five-hole pitch-yaw probe and a three-hole boundary layer probe. The probes were also installed in the Station 2 survey plane located approximately 7.0 percent axial-chord downstream of the blade trailing edge. The survey probe traversed three blade passages and half the span of the blade. For the two inlet angles considered in this study, pitchwise/spanwise surveys were taken which consisted of 26 spanwise surveys with 62 pitchwise points. The overall estimated uncertainty in flow angle was $\pm 1.5^{\circ}$ and the overall estimated uncertainty in total-pressure coefficient was \pm 0.8 percent (Ref. 17).

The main measurement blades 4,5 , and 6 , shown in Figure 2, were instrumented with static pressure taps at four spanwise locations. Blade 5 was fully instrumented with 44 taps along 10, 15, 30, and 50 percent of span.

\section{Computational Method}

The computations of exit total pressure, exit flow angles and blade pressure distribution were made using the code GlennHT (Ref. 19) on structured grids. The transition/turbulence model of Walters and Leylek was used for the computations (Ref. 11).

\section{Glenn-HT Computer Code}

The computer code used in this work is the Glenn-HT code (Ref. 19). Glenn-HT is a Fortran 90 code. It uses structured multi-block grids. It is designed to be a multi-physics code and is currently capable of solving solid conduction and compressible fluid flow. To arrive at a steady solution, a finite- volume form of the unsteady compressible ReynoldsAveraged Navier-Stokes (RANS) equations are integrated in pseudo-time using an explicit Runge-Kutta solver in a multigrid driver. For the present exercise, the convective fluxes were discretized with a second order upwind scheme described in Reference 20. The diffusive terms were discretized using a second-order central differencing. The convective terms of the turbulence model equations were modelled using a first-order upwind method.

\section{Computational Grid}

The grids used in this work were generated using GridPro (Program Development Corporation) (Ref. 21). The software used an elliptic solver to smooth an initial, algebraically generated, multi-block grid.

For the VSPT blade, taking advantage of the symmetry of the passage for the three-dimensional grid, only half of the span was gridded. The grid was constructed using multiple blocks in three-dimensional. As is the practice with grid generation when using GridPro, an inviscid grid was generated first and subsequently viscous grid was generated by clustering. The grid was clustered near the blade and the endwall surfaces. The spacing was chosen such that the first grid line away from the wall was at a dimensionless wall distance $\left(y^{+}\right)$of near unity.

Two grids were generated: Grid1 had 2 million nodes and Grid2 has approximately 7 million nodes. Both Grid1 and Grid2 used a clustering factor of 1.1 away from the walls (space at the wall $2 \times 10^{-5} C_{x}$ ). Grid2 was further refined in the spanwise direction (by about a factor of 1.5) to better capture three-dimensional spanwise effects. The streamwise direction was further refined around the blade to allow enhanced resolution of possible transition and/or separation, flow structures in the pressure-side cove and trailing edge, and wake flow. Enhanced resolution of the trailing circle was achieved by using 16 points in Grid 1 versus 24 points for Grid2 around the trailing edge circle.

Figure 3 shows the three-dimensional grid corresponding to Grid2 described above. The inlet plane was situated about half an axial-chord upstream to coincide with the measurement stations (Tables 2 and 3). The downstream boundary was placed at 1.5 axial-chord distance downstream of the leading edge. A third grid was also used for ensuring grid convergence by coarsening Grid 2 by a factor of 2 in each index direction. 


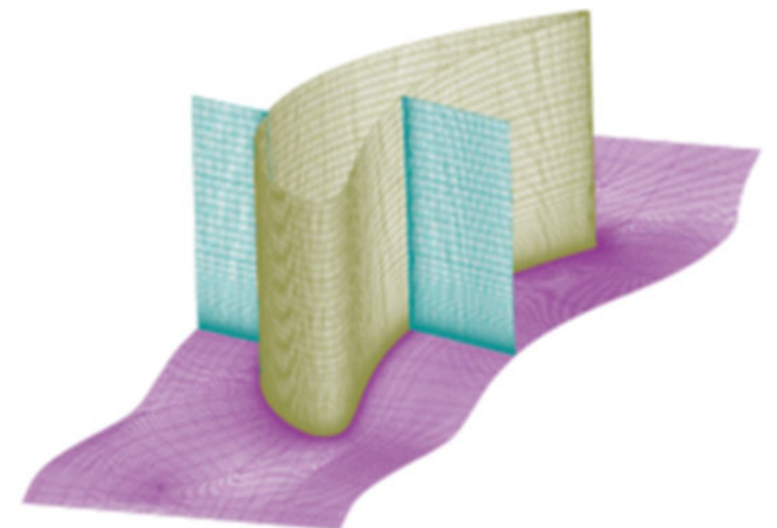

Figure 3.-Typical three-dimensional grid for VSPT.

\section{Boundary Conditions}

The information listed in Tables 2 and 3 were used to specify the boundary conditions. Briefly, the exit boundary condition was a constant pressure boundary condition and was set according to the pressure ratio shown in Table 3 . At the inlet, the boundary layer thickness was used to estimate a friction velocity (Ref. 22). Using the law of the wall/wake, a velocity profile was obtained which was subsequently converted into a total pressure profile. In the free stream, the measured turbulence intensity and the turbulence length scale were used to specify the inlet conditions for the turbulence kinetic energy and specific dissipation ( $k$ and $\omega)$. The laminar kinetic energy, a variable in the Walters-Leylek turbulence model, was set to a very small value. A stable and satisfactory profile was established by specifying the inlet conditions in the free stream and allowing turbulence quantities to be extrapolated upstream within the boundary layer.

The turbulence length scale, as specified in computations of turbulent flows, represents the size of energy- containing eddies and is often specified as a percentage of a relevant length scale such as the passage span or blade axial chord. Values between 1 to 10 percent are customarily used. In the present study, available data were used to compute the length scale as described below.

\section{Length Scale Computation}

In order to ascertain the appropriate value for the length scale which establishes the decay rate, computations were made using a three-dimensional sliver grid similar to the grid in Figure 3 covering the blade but having the upstream boundary at -5.0 axial-chord upstream. By iteratively adjusting the upstream value of the turbulence length scale, the turbulence level at the second location at $-0.5 C_{x}$ was matched. The length scale computed at the second location was used as a boundary condition for the three-dimensional computations to follow. For the rest of the computations (including the takeoff incidence angle) for which the upstream boundary was placed at $-0.5 C_{x}$, the measured turbulence intensity of 0.3 percent and length scale of 0.3 percent of span were used.

\section{Results}

Post-diction results for the cruise and takeoff conditions are presented in this section. Results will be presented for blade pressure distribution, total-pressure coefficients, and exit flow angle distribution.

\section{Cruise Angle}

As listed in Table 2, at the cruise angle, the blade was tested at a positive incidence $\left(i=+5.8^{\circ}\right)$. Although the Reynolds number is $\operatorname{Re}_{C x, 2}=5.3 \times 10^{5}$, absence of free-stream turbulence makes this case difficult to compute as the flow tends to be transitional and prone to separation.

\section{Pressure Distribution}

A comparison of the computed and measured blade pressure distributions would indicate the efficacy of the transition model; the boundary layer flow tends to be transitional and prone to separation and, hence, the presence or absence of separation affects the pressure distribution. Separation effects were reflected in the blade surface pressure distribution making the experimental comparisons useful for evaluating the model.

Grid resolution adequacy for prediction of blade loading, usually less of a factor for attached flows, was investigated via a grid resolution study and the solutions were found to be grid independent; thus, only one solution is shown. As seen in Figure 4 overall, good agreement is seen between the computation and the experimental data. The data at midspan (black circles) suggest a suction-side separation occurring at $x / C_{x}=0.7$, as evidenced by a plateau. The computations (black line) fail to capture the plateau. At $x / C_{x}=0.7$, a discontinuity in the slope of the computed suction-side pressure is noted. Figure 5, shows the magnitude of the velocity gradient at midspan on both the pressure and suction surfaces. On the suction-side, transition occurs at 40 percent axial-chord. Such early transition would reduce the potential for boundary-layer separation on the suction-side. On the pressure-side agreement with data is excellent. The pressure-side appears to have transitioned at 35 percent axial-chord.

Pressure loadings at other span locations are important to examine for this three-dimensional flow due to the thick inlet boundary layer. It is observed that the computed loading as shown in Figure 4, agree well with data in other span locations. Although there is a dearth of data on the suctionside, near the trailing edge at other spanwise locations, the computations in Figure 4 appear to go through those data points. 


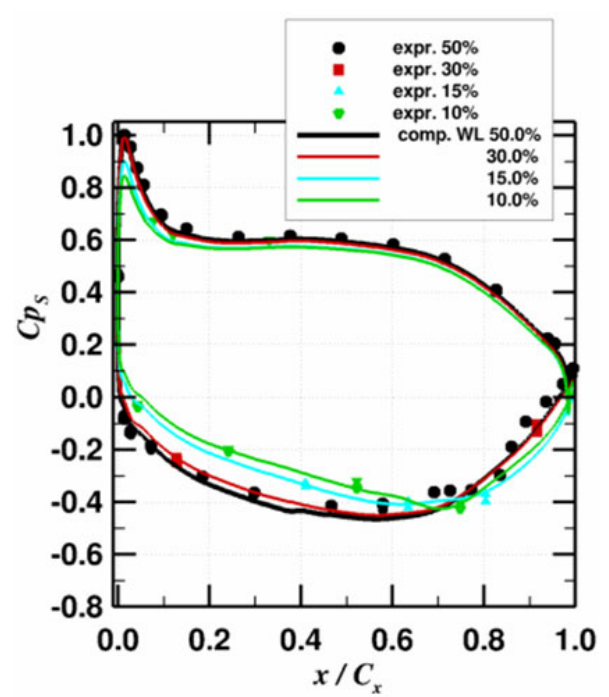

Figure 4.-Pressure distributions at cruise $\left(i=5.8^{\circ}\right)$ for four span locations and comparison with data (Ref. 17).

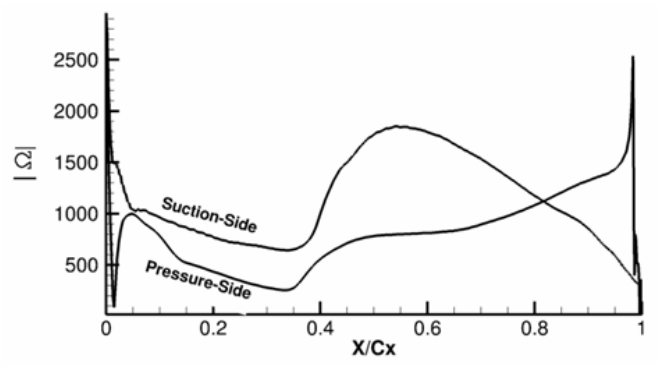

Figure 5.-Computed dimensionless magnitude of the velocity gradient on the blade surface at midspan for cruise incidence.

\section{Exit Total Pressure}

Total pressure was surveyed at 7 percent chord downstream of the trailing edge in Reference 17. Figure 6(a) shows the measured contours and 6(b) shows the computed contours at the same axial position. The passage is periodic and the mismatch in location is due to the shape of the computational domain. Inspection of Figure 6(b) reveals major areas of elevated loss. One area is the loss core due to the pressure side leg of the horseshoe vortex, shown prominently, corresponds to the experimental data at $(-0.55,0.38)$. Another is the region in the wake of the blade, corresponding to the region $(-0.55$, $0.5)$ due to the separated flow in the vicinity of midspan. And the third region is close to the hub and is due to the wake and endwall boundary layer interaction corresponding to Figure 6(a) near $(-0.5,0.02)$. Qualitative agreement exists between Figure 6(a) and (b). Quantitative agreement is good near the endwall.

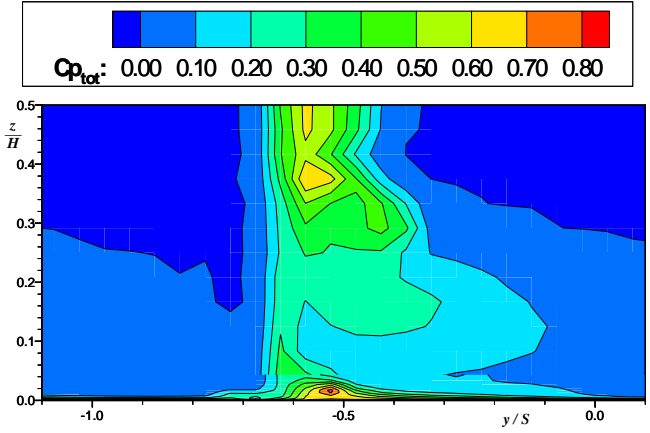

(a)

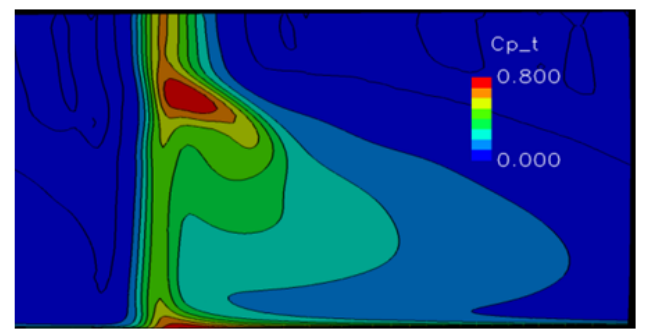

(b)

Figure 6. $-C p_{t}$ contours for the cruise incidence $\left(i=5.8^{\circ}\right)$ at 0.07 axial-chord downstream of the trailing edge; (a) data from (Ref. 17) and (b) computed.

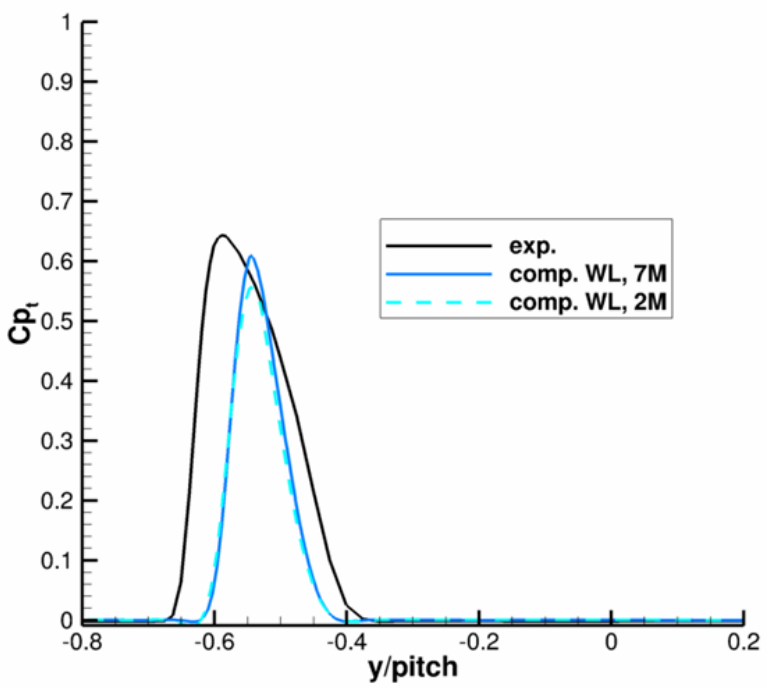

Figure 7.-Total pressure loss 0.07 axial-chord downstream of midspan (Ref. 17) and comparison with CFD computations.

Computed and measured midspan total pressure coefficient at midspan are compared in Figure 7. For the computational result, two computational grids using 2 and 7 million grid points were shown with good agreement. Comparison with experiment shows the lack of agreement coming from the early transition and absence of separation zone in the computations. 


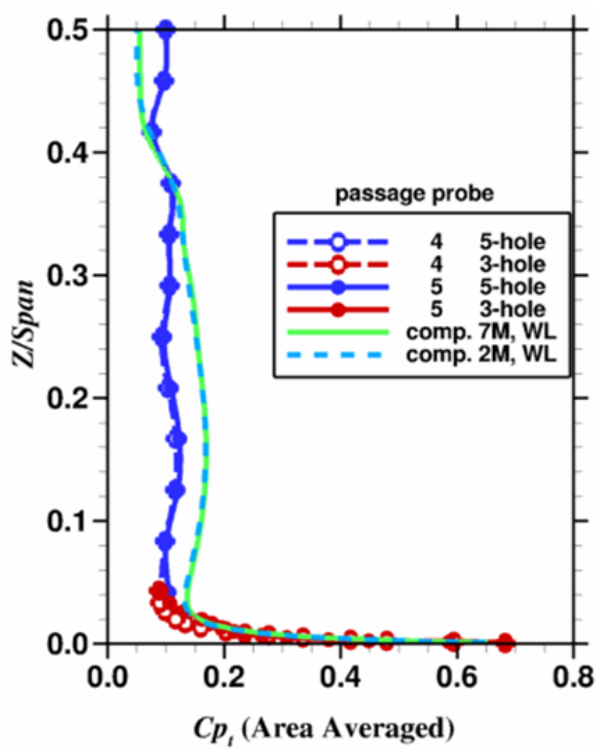

Figure 8.-Area averaged losses at 7 percent axial-chord downstream of the blade at cruise incidence.

Figure 8 shows experimentally determined pitch-averaged total pressure coefficient for the cruise condition for two adjacent passages (to verify periodicity), and the integrated computational results. While the CFD results at the two grid resolutions agree well, the calculated total pressure coefficient at midspan is lower than measured, consistent with Figure 7. The total pressure coefficient was overpredicted below 30 percent span.

\section{Exit Angle Comparison}

In Reference 17, the pitchwise mass-averaged exit flow angle, $\beta$, is presented. The computed angles were similarly mass-averaged and presented in Figure 9. The computational results for the two grids agree very well. Agreement between the experiments and CFD is to within a degree which is of the order of the measurement uncertainty. In the highly overturned region very near the endwall the agreement diminishes to within $2^{\circ}$ to $2.5^{\circ}$, which is slightly outside the uncertainty range of the experiments.

\section{Takeoff Angle}

At takeoff, the incidence angle is $-36.7^{\circ}$.

\section{Pressure Distribution}

Figure 10 shows the static pressure coefficient for the blade at highly negative incidence $\left(-36.7^{\circ}\right)$. The negative incidence gives rise to an inverted pressure distribution in the leading edge region of the blade. The loading reverts to nominal beyond 20 percent axial-chord from leading edge. The pressure distribution plot shows good agreement between the

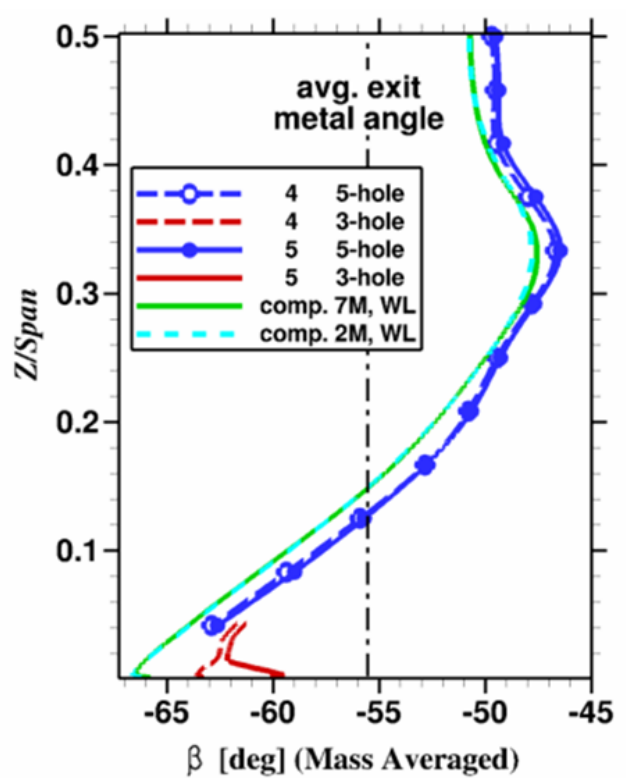

Figure 9.-Mass Averaged pitchwise exit angle at 7 percent axial-chord downstream of the blade at cruise incidence.

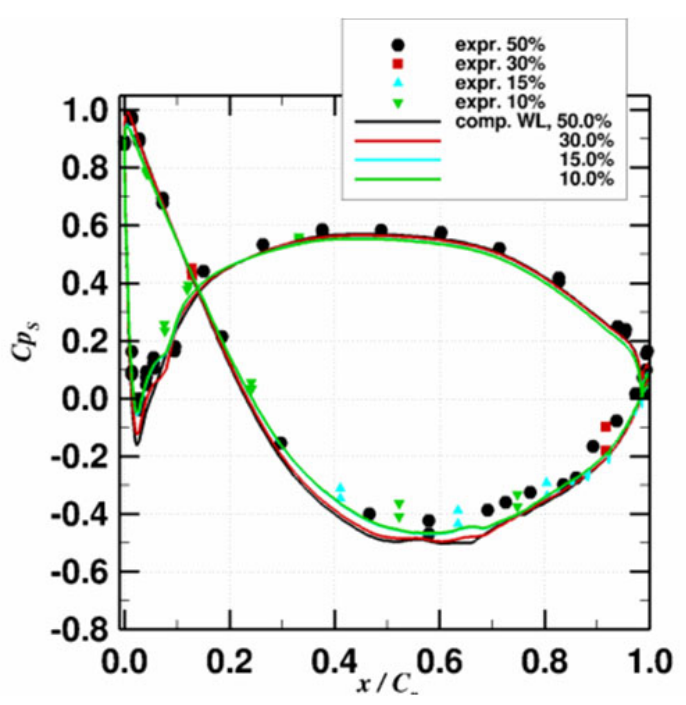

Figure 10.-Pressure distribution at takeoff for four span locations and comparison with data from Reference 17.

computations and the experiment. The two refined grids gave the same result and only one is shown. Magnitude of the velocity gradient at the blade surface, plotted in Figure 11, along the blade midspan, shows a local pressure-side separation bubble between $x / C_{x}$ values of 0.05 to 0.075 . A red semicircle highlights the bubble. In Figure 10, the location of the local minimum and the magnitude of the static pressure coefficient on the pressure-side are nicely captured and the profile downstream is also well represented. Good agreement with the data is shown for the suction surface. As at cruise incidence, the kink in the data near $x / C_{x}=0.7$, presumably due 


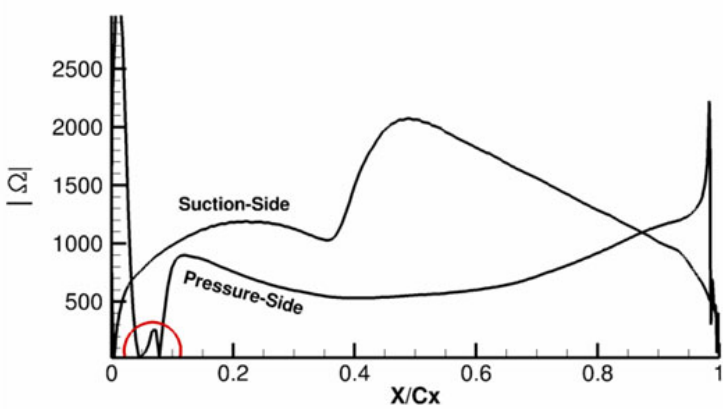

Figure 11.-Computed dimensionless magnitude of the gradient of velocity at the blade surface at midspan for takeoff incidence.

to separation, is missed. Inspection of the velocity gradient along the suction-side of the blade in Figure 11 indicates transition took place at 40 percent axial-chord and thus reduced the possibility of a downstream separation.

\section{Exit Total Pressure}

Figure 12(a) and (b) show the experimental and computed contour plots of the total-pressure coefficient at 7 percent chord downstream of the trailing edge. One of the consequences of the unloading of the blade is the weakened secondary flow system in the passage and reduced variation in pressure loading in the spanwise direction. The contours appear different than those for the takeoff incidence. The pressure-side leg of horseshoe vortex, in Figure 12(a), can be seen to be present in the lower portion of the blade span, at $(-0.5,0.15)$, due to the weakening of the passage vortex. The endwall wake interaction is still present and the total pressure coefficient local maximum is located at $(-0.5,0.02)$. The computed results agree qualitatively with the experiment and all those features are present and are generally in the correct relative positions.

Figure 13 shows the experimentally measured total pressure distribution across the wake at the midspan. The computations agree with the size of the wake at midspan as the integrated average shown in Figure 14 shows good agreement with the experimental data.

Figure 14 shows the pitchwise integrated total-pressure coefficient at the $x / C_{x}=1.07$ plane both experimentally and computationally. To help verify periodicity, two adjacent passages 4 and 5 were reported in Reference 17, as shown in the legend. The agreement between the computed grids is quite good, as is the agreement between the computed and the experimental results. This may be due to the absence of large secondary flow structures in the passage and the apparent absence or weakness of the suction-side separation bubble at midspan.

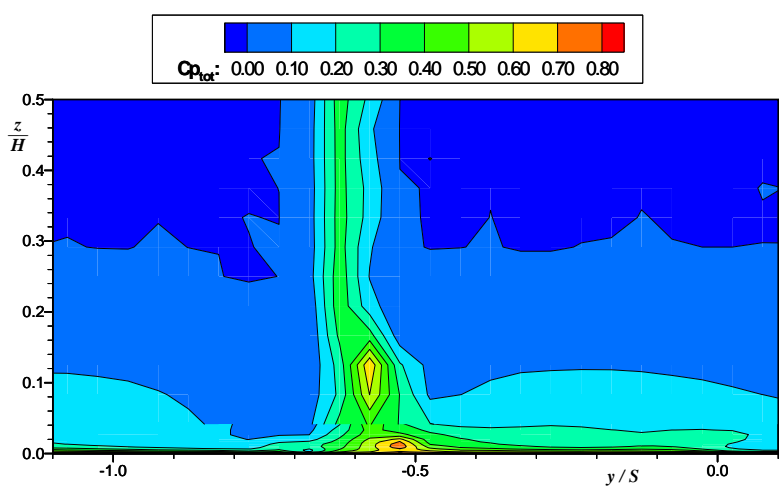

(a)

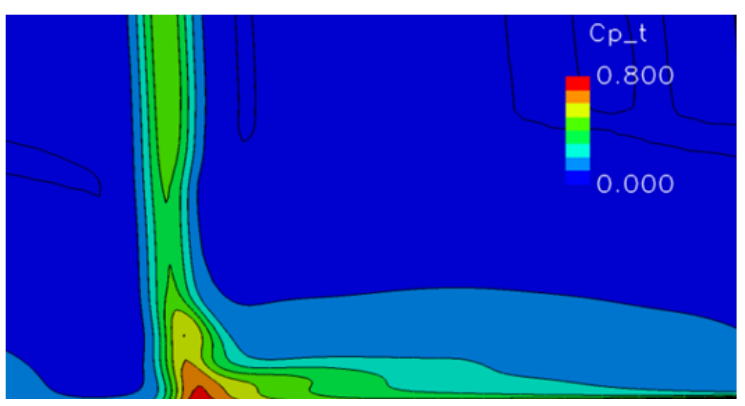

(b)

Figure 12. $-C_{p t}$ contours for the takeoff incidence ( $i=$ -36.7 ) at 0.07 axial-chord downstream of the trailing edge (a) from (Ref. 17) and (b) computed.

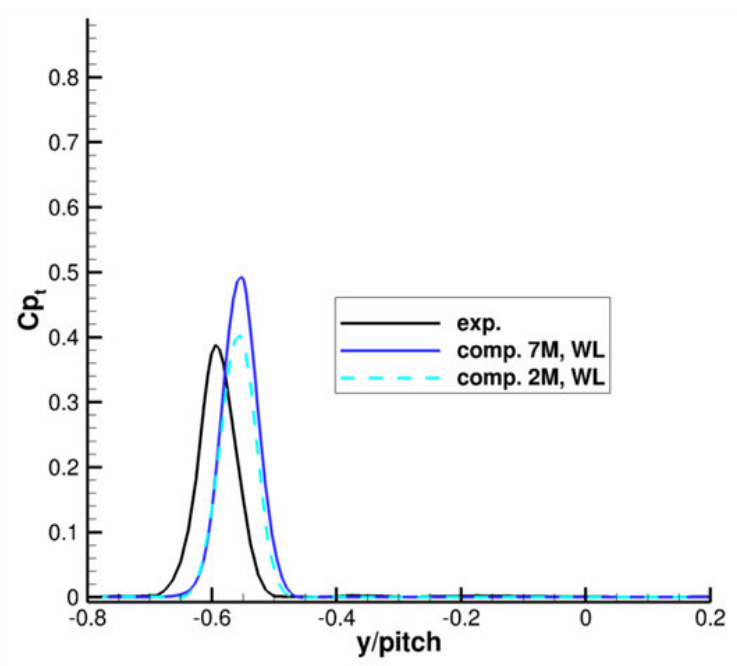

Figure 13.-Total pressure loss 0.07 axial-chord downstream of midspan for the takeoff incidence (Ref. 17) and comparison with CFD computations. 


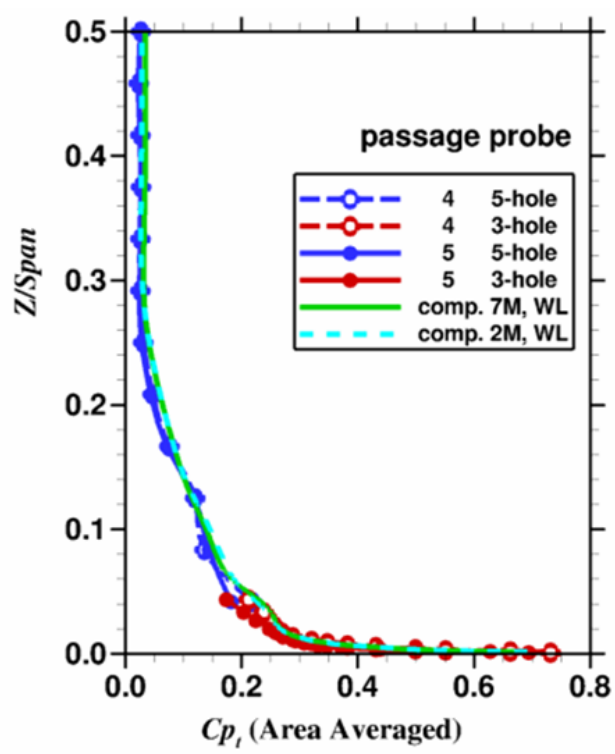

Figure 14.-Area averaged losses at 7 percent axial chord downstream of the blade at cruise condition.

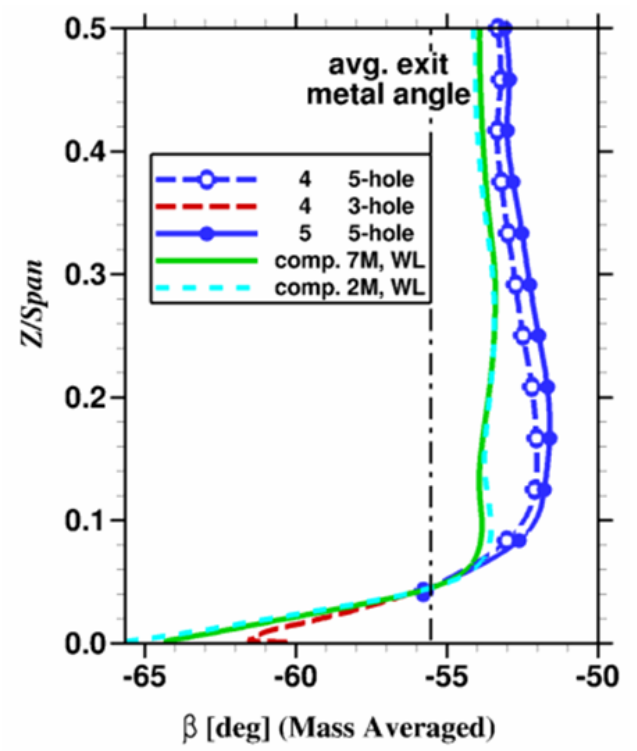

Figure 15.-Mass Averaged pitch angle at 7 percent axial chord downstream of the blade.

\section{Exit Angle Comparison}

The pitch angle, $\beta$, was also computed and compared to the measured values. The data and comparison to the CFD computations are presented in Figure 15. The agreement between the two grids is very good. The variance between the CFD and the measured values is no more than $2^{\circ}$ except for very near the endwall where the apparent variance is larger. In the highly overturned region very near the endwall the agreement diminishes to within $2^{\circ}$ to $2.5^{\circ}$ which is slightly outside the uncertainty range of the experiments.

\section{Summary}

For the VSPT, flow transition/separation has been identified as an important process. Large variations in incidence angles require models that can reasonably compute these flows. Numerical modeling of the three-dimensional flow in a twodimensional transonic linear cascade was performed at the two incidence angle conditions corresponding to takeoff and cruise for which experimental data (Ref. 17) were available. The inlet length scale, which determines the decay rate of turbulence, was determined from the data. Three-dimensional blade loadings agreed with the data except for the aft 30 percent of the suction-side, where CFD missed a laminar separation. As for the total-pressure survey downstream of the blade, agreement with the data was obtained to within 50 percent for the cruise incidence angle while for the takeoff incidence the agreement was excellent. Agreement with the exit flow angle measurements was good and was mostly within about a degree for the cruise angle and less than two degrees for the takeoff angle which is fair. Near the endwall the error was as high as $2.5^{\circ}$.

Further assessment of the Walter-Leylek model is necessary for the determination of the source of the deficiency in the transition submodel.

\section{References}

1. Johnson, W., Yamauchi, G.K., and Watts, M.E., 2005, "NASA Heavy Lift Rotorcraft Systems Investigation," NASA/TP-2005-213467.

2. Acree, C.W., Hyeonsoo, Y., and Sinsay, J.D., 2008, "Performance Optimization of the NASA Large Civil Tiltrotor," Proc. Int. Powered Lift Conf., London, UK, July 22-24.

3. Stevens, M.A., Handschuh, R.F., Lewicki, D.G., 2009, "Variable/Multispeed Rotorcraft Drive System Concepts," NASA/TM-2009-215456; also ARL-TR4728.

4. Welch, G.E., 2010, "Assessment of Aerodynamic Challenges of a Variable-Speed Power Turbine for Large Civil Tilt-Rotor Application," Proc. AHS Int. 66th Annual Forum, May; also NASA/TM-2010216758, Aug.

5. Gier, J., Franke, M., Hübner, N., Shröder, T., 2008, "Designing LP Turbines for Optimized Airfoil Lift," ASME-GT2008-51101.

6. Haselbach, F., Schiffer, H.-P., Horsman, M., Dressen, S., Harvey, N., Read, S., 2002, "The Application of Ultra High Lift Blading in the BR715 LP Turbine," ASME Journal of Turbomachinery Volume 124, 4551.

7. Hourmouziadis, J., 1989, "Aerodynamic Design of Low Pressure Turbines," in Blading Design for Axial Turbomachines, AGARD-LS-167, pp. 8-1 to 8-40. 
8. Welch, G.E., 2011, "Computational Assessment of the Aerodynamic Performance of a Variable-Speed Power Turbine for Large Civil Tilt-Rotor Application," Proceedings AHS Int. Forum 67, May 35; also NASA/TM-2011-217124.

9. Ameri, A., 2012 "Use of Transition Modeling to Enable the Computation of Losses for the VariableSpeed Power Turbine," GT2012-69591, Turbo Expo, Copenhagen, Denmark.

10. Walters, D.K. and Leylek, J.H., 2004, “A New Model for Boundary Layer Transition Using a Single-Point RANS Approach," ASME Journal of Turbomachinery, Volume 126, Issue 1, 193.

11. Walters, D.K. and Leylek, J.H., 2005, “Computational Fluid Dynamics Study of Wake-Induced Transition on a Compressor-Like Flat Plate," ASME Journal of Turbomachinery, Volume 127, Issue 1, 52 (12 pages).

12. Timko, L.P., 1984, "Energy Efficient Engine High Pressure Turbine Component Test Performance Report," NASA CR-168289.

13. McVetta, A., B., Giel, P.1 W., Welch, G.E., 2012, "Aerodynamics Investigation of Incidence Angle Effects in a Large Scale Transonic Turbine Cascade," AIAA-2012-3879, July, 2012, Atlanta, GA., USA.

14. Welch, G.E., McVetta, A.B., Stevens, M.A., Howard, S.A., Giel, P.W., Ameri, A.A., To, W., Skoch, G., J. and Thurman, D.R., 2012, "Variable-Speed Power Turbine Research at Glenn Research Center," Proc. AHS Int. $68^{\text {th }}$ Annual Forum, May 1-3; also NASA/TM-2012-217605.
15. Cutrone, L., De Palma, P. Pascazio, G. Napolitano M., 2007, "An evaluation of bypass transition models for turbomachinery flows," International Journal of Heat and Fluid Flow, 28, pp. 161-177.

16. Cutrone, L., De Palma, P., Pascazio, G., Napolitano, M., 2008, "Predicting transition in two- and threedimensional separated flows," Int. Journal of Heat and Fluid Flow, Volume 29, pp. 504-526.

17. McVetta, A.B., Giel, P.W, Welch, G.E., 2013, "Aerodynamic Measurements of a Variable-Speed Power-Turbine Blade Section in a Transonic Turbine Cascade at Low Inlet Turbulence," GT2013-94695, to be presented at 2013 ASME Turbo Expo.

18. Ford, A., Bloxham, M., Turner, E., Clemens, E. and Gegg, S., 2012, "Design Optimization of IncidenceTolerant Blading Relevant to Large Civil Tilt-Rotor Power Turbine Applications," NASA/CR-2012217016, Dec.

19. Steinthorsson, E., Liou, M.S., and Povinelli, L.A., 1993, "Development of an Explicit Multiblock/Multigrid Flow Solver for Viscous Flows in Complex Geometries," AIAA-93-2380; also NASA TM-106356.

20. Hunyh, H.T., 1996, "Accurate Upwind Methods for Euler Equation," SIAM J. Numer. Anal., Vol.32, No. 5, pp. 1565-1619.

21. GridPro, Program Development Corporation, White Plains, N.Y.

22. White, Frank, M., 1991, Viscous Fluid Flow, Second Edition, McGraw-Hill Inc., New York. 



\begin{tabular}{|c|c|c|}
\hline \multicolumn{2}{|c|}{ REPORT DOCUMENTATION PAGE } & $\begin{array}{l}\text { Form Approved } \\
\text { OMB No. 0704-0188 }\end{array}$ \\
\hline \multicolumn{3}{|c|}{ 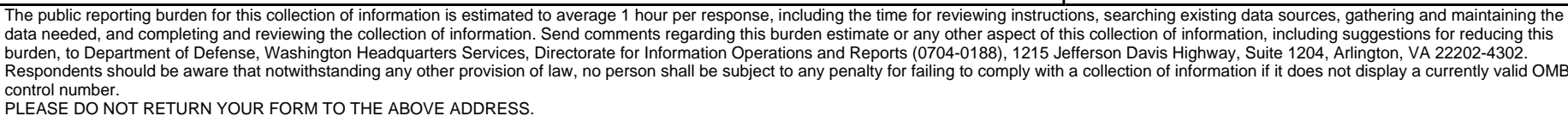 } \\
\hline $\begin{array}{l}\text { 1. REPORT DATE (DD-MM-YYYY) } \\
01-05-2013\end{array}$ & $\begin{array}{l}\text { 2. REPORT TYPE } \\
\text { Technical Memorandum }\end{array}$ & 3. DATES COVERED (From - To) \\
\hline \multirow{3}{*}{\multicolumn{2}{|c|}{$\begin{array}{l}\text { 4. TITLE AND SUBTITLE } \\
\text { Validation of a CFD Methodology for Variable Speed Power Turbir }\end{array}$}} & 5a. CONTRACT NUMBER \\
\hline & & 5b. GRANT NUMBER \\
\hline & & 5c. PROGRAM ELEMENT NUMBER \\
\hline \multirow{3}{*}{\multicolumn{2}{|c|}{$\begin{array}{l}\text { 6. AUTHOR(S) } \\
\text { Ameri, Ali, A.; Giel, Paul, W.; McVetta, Ashlie, B. }\end{array}$}} & 5d. PROJECT NUMBER \\
\hline & & 5e. TASK NUMBER \\
\hline & & $\begin{array}{l}\text { 5f. WORK UNIT NUMBER } \\
\text { WBS 877868.02.07.03.01.02.01 }\end{array}$ \\
\hline \multicolumn{2}{|c|}{$\begin{array}{l}\text { 7. PERFORMING ORGANIZATION NAME(S) AND ADDRESS(ES) } \\
\text { National Aeronautics and Space Administration } \\
\text { John H. Glenn Research Center at Lewis Field } \\
\text { Cleveland, Ohio 44135-3191 }\end{array}$} & $\begin{array}{l}\text { 8. PERFORMING ORGANIZATION } \\
\text { REPORT NUMBER } \\
\text { E-18653 }\end{array}$ \\
\hline \multirow{2}{*}{\multicolumn{2}{|c|}{$\begin{array}{l}\text { 9. SPONSORING/MONITORING AGENCY NAME(S) AND ADDRESS(ES) } \\
\text { National Aeronautics and Space Administration } \\
\text { Washington, DC 20546-0001 }\end{array}$}} & $\begin{array}{l}\text { 10. SPONSORING/MONITOR'S } \\
\text { ACRONYM(S) } \\
\text { NASA }\end{array}$ \\
\hline & & $\begin{array}{l}\text { 11. SPONSORING/MONITORING } \\
\text { REPORT NUMBER } \\
\text { NASA/TM-2013-217860 }\end{array}$ \\
\hline \multicolumn{3}{|c|}{$\begin{array}{l}\text { 12. DISTRIBUTIONIAVAILABILITY STATEMENT } \\
\text { Unclassified-Unlimited } \\
\text { Subject Categories: } 07 \text { and } 34 \\
\text { Available electronically at http://www.sti.nasa.gov } \\
\text { This publication is available from the NASA Center for AeroSpace Information, 443-757-5802 }\end{array}$} \\
\hline
\end{tabular}

\section{SUPPLEMENTARY NOTES}

\section{ABSTRACT}

Analysis tools are needed to investigate aerodynamic performance of Variable-Speed Power Turbines (VSPT) for rotorcraft applications. The VSPT operates at low Reynolds numbers (transitional flow) and over a wide range of incidence. Previously, the capability of a published three-equation turbulence model to predict accurately the transition location for three-dimensional heat transfer problems was assessed. In this paper, the results of a post-diction exercise using a three-dimensional flow in a transonic linear cascade comprising VSPT blading are presented. The measured blade pressure distributions and exit total pressure and flow angles for two incidence angles corresponding to cruise $\left(i=5.8^{\circ}\right)$ and takeoff $\left(i=-36.7^{\circ}\right)$ were used for this study. For the higher loading condition of cruise and the negative incidence condition of takeoff, overall agreement with data may be considered satisfactory but areas of needed improvement are also indicated.

\section{SUBJECT TERMS}

Power turbine; Low pressure turbine; Turbulence modeling; Computational Fluid Dynamics (CFD); Validation

\begin{tabular}{|c|c|c|c|c|c|}
\hline \multicolumn{3}{|c|}{ 16. SECURITY CLASSIFICATION OF: } & \multirow{2}{*}{$\begin{array}{l}\text { 17. LIMITATION OF } \\
\text { ABSTRACT } \\
\text { UU }\end{array}$} & \multirow{2}{*}{$\begin{array}{l}\text { 18. NUMBER } \\
\text { OF } \\
\text { PAGES } \\
18\end{array}$} & \multirow{2}{*}{$\begin{array}{l}\text { 19a. NAME OF RESPONSIBLE PERSON } \\
\text { STI Help Desk (email:help@sti.nasa.gov) } \\
\text { 19b. TELEPHONE NUMBER (include area code) } \\
\text { 443-757-5802 }\end{array}$} \\
\hline $\begin{array}{l}\text { a. REPORT } \\
U\end{array}$ & $\begin{array}{l}\text { b. ABSTRACT } \\
U\end{array}$ & $\begin{array}{l}\text { c. THIS } \\
\text { PAGE } \\
\text { U }\end{array}$ & & & \\
\hline
\end{tabular}



